Business \& Entrepreneurship Journal, Vol. 11, No. 1, 2022, 27-36

ISSN: 2241-3022 (print version), 2241-312X(online)

https://doi.org/10.47260/bej/1112

Scientific Press International Limited

\title{
Decentralized Environmental Regulation with Agglomeration Forces
}

\author{
Mitch Kunce ${ }^{1}$
}

\begin{abstract}
Convention, in the setting of interjurisdictional economic competition, envisions a race-to-the-bottom when decentralized jurisdictions, in their eagerness to attract commerce, introduce policies to reduce business costs in the form of tax structures that under-provide local public goods and lax pollution standards that lower environmental quality. The current body of empirical evidence, however, does not provide compelling support for the race within the context of environmental federalism. The theoretical work presented herein debits the inventory of literature questioning the race-to-the-bottom claim by introducing agglomeration forces into the standard model. When agglomeration influences are weak to moderate, the race is still on. Conversely, when agglomeration forces are strong, fiscal competition influences are mitigated therefore providing jurisdiction's incentives to strengthen local environmental standards.
\end{abstract}

JEL classification numbers: H73, R12, R30.

Keywords: Environmental federalism, Interjurisdictional competition, External economies of scale.

${ }^{1}$ DouglasMitchell Econometric Consulting Laramie, WY USA.

Article Info: Received: January 27, 2022. Revised: February 9, 2022.

Published online: February 11, 2022. 


\section{Introduction}

The issue regarding the appropriate assignment of fiscal functions among the various levels government is still much debated, yet mostly unresolved. For example, which level of government should be assigned the responsibility for environmental quality? In the case of purely localized pollution effects, decentralized authority has been touted appropriate and in certain circumstances welfare enhancing (Oates 2002). In contrast, many contend that decentralized control leads to destructive competition among jurisdictions (Cumberland 1981). Those in this camp forward that local governments, in an attempt to lure mobile capital to increase production, will compete with each other by offering fiscal inducements-generally in the form of lower capital taxes and/or lax environmental standards. This literature, based on the work of Oates and Schwab (1988), demonstrates that local governments make environmental decisions that are closely intertwined with jurisdictional tax policy. When price-taking jurisdictions are restricted to the use of source-based capital taxation, local public goods are under-provided and this fiscal inefficiency distorts the choice of environmental standards.

In this light, consider the possibility that attracting new capital investment yields benefits to a jurisdiction beyond raw increases in production. That is, the accumulation of capital augments the productivity of a jurisdiction. These benefits result from economic agglomeration forces. The importance of agglomeration economies to the formation of communities and regions is the subject of an accomplished literature (see Henderson 1988 and Krugman 1991 for reviews). Moreover, a small literature now exists integrating agglomeration into the standard tax competition model, but these attempts ignore the joint determination of tax policy and environmental standards (see Krogstrup 2008 for a review). These contributions generally find that agglomeration forces tend to exacerbate the public good welfare inefficiencies. In a related vein, theoretical work by Zeng and Zhao (2009) incorporate industrial agglomeration in a trans-boundary pollution model showing that agglomeration forces cause capital to become 'sticky' in response to countries whose environmental standards have been lowered, coined "pollution havens". However, the buried lead in Zeng-Zhao's paper is that agglomeration forces allow a country to slightly raise environmental quality without experiencing capital flight.

In exploring the potential importance of agglomeration forces in determining devolved environmental standards, the aim of this paper is to incorporate external economies into the framework developed by Oates and Schwab (1988). Agglomeration forces are modeled as multiplicative external increasing returns in accumulated jurisdictional capital. Following Krogstrup (2008), firms in a jurisdiction operate under constant-returns-to-scale where an increase in capital has productivity effects on all firms in the jurisdiction. Conversely, local authorities possess complete information regarding agglomeration effects and use this information when choosing utility maximizing capital tax rates and environmental 
standards. The introduction of external economies expands the feasibility of varying levels of environmental quality outcomes. In the model, mobile capital is paid its net-of-tax marginal product. How this marginal product changes when additional capital is employed becomes central to the analysis. If agglomeration influences are weak to moderate, the marginal product of capital diminishes and environmental standards are set below a social optimum. In contrast, if agglomeration forces are strong and dominate diminishing capital productivity effects, environmental standards become overly strict. The model is fully developed in the next section where taxation and environmental quality optimal conditions are characterized. The third section forwards three central propositions while conclusions and empirical implications are drawn in section four.

\section{The Model}

The national economy is made up of many homogenous jurisdictions where agglomeration forces are present. ${ }^{2}$ Areas are small enough that their decision making is deemed competitive yet large enough that pollution generated in one jurisdiction does not spill-over into another. ${ }^{3}$ Firms in a jurisdiction produce a numeraire private good, $Q$, that is sold in a national market. Production requires mobile capital, $K$, labor, $L$, and pollution emissions, $E$, which are treated as nonpurchased inputs analogous to Oates and Schwab (1988). Local authorities set an aggregate level of $E$ which is allocated to firms based on labor input proportions. Residents of a jurisdiction are identical, fixed and inelastically supply labor to production. Normalizing identical firms and households to one, jurisdictional constant-returns-to-scale production takes the form, ${ }^{4}$

$$
Q=F(L, K, E)=L f(k, e)=f(k, e),
$$

where $f_{k}, f_{e}>0$ and $f_{k k}, f_{e e}<0$. Subscripts denote partial derivatives. Similar to Fernández (2005), agglomeration economies will augment production as external forces deriving from the aggregate level of capital invested per jurisdictional resident. The function $a(k)$ represents external economies-of-scale of capital accumulation in a specific jurisdiction. When making decisions regarding inputs and output, firms treat $a(k)$ as a given parameter. Augmented aggregate production becomes,

\footnotetext{
${ }^{2}$ Homogeneity avoids Tiebout-type inefficiencies. Moreover, the model focuses on allocative rather than distributive questions. If inefficiencies arise in a homogenous setting, they are likely to be exacerbated in a heterogeneous construct.

3 'Small' presumes a competitive not strategic model. See Kunce and Shogren (2002) and Kunce (2022) for examples of game-theoretic models of environmental federalism. See List and Mason (2001) for a model that addresses transboundary pollution.

${ }^{4}$ To simplify the exposition, subscripts denoting jurisdictions will be suppressed with few exceptions.
} 


$$
q=f(k, e) a(k),
$$

where $a(k)>1$ and $a_{k}>0$. Integral to equation (2), firms operate under constantreturns-to-scale yet an increase in capital has productivity effects on all firms in the jurisdiction.

There is a fixed stock of capital in the economy that is mobile within and across jurisdictions (at least in the long run). Following convention, the model focuses on location choices rather than new capital formation or market entry. Profit maximizing forces distribute mobile capital until net returns are equalized across all jurisdictions. Capital receives its marginal product less a unit tax $t$ where,

$$
r=f_{k}(k, e) a(k)-t=f_{k} a-t .
$$

Competitive firms and 'small' jurisdictions view $r$ as exogenous. Each jurisdiction finances a local Samuelsonian public good with capital taxation where,

$$
G=t k
$$

This approach is convention in the vast tax competition literature because local governments believe that private production is sufficiently capital intensive and attempt to stimulate capital investment using tax policies (Wilson 1986). ${ }^{5}$

The normalized representative resident's income/consumption is defined,

$$
x=y+f(k, e) a(k)-k f_{k}(k, e) a(k)=y+f a-k f_{k} a,
$$

or when using equations (3) and (4),

$$
x=y+f a-r k-G,
$$

where y denotes any exogenous income including any net returns from capital ownership.

Residents of a jurisdiction receive utility from consumption and local public goods, but suffer disutility from the level of allowed pollution emissions. Normalized jurisdictional utility takes the form, $u(x, G, e)$, where $u_{x}$ and $u_{G}>0$, but $u_{e}<0$. Higher $e$ corresponds to poorer environmental quality where $e$ represents a pure public bad. In keeping with the Arrow-Debreu (Wilson 1999) separation assumption for general equilibrium constructs, residents have two distinct roles in the model. First, as consumers, they seek to maximize utility over a bundle of goods

5 The propositions below will explore more diverse local taxing regimes. 
and public services. Second, supplying labor inputs and in return receiving income for consumption. More of the mobile factor and lax environmental standards enhance local production and can provide residents with higher incomes hence more consumption. However, in order to attract the mobile factor, the jurisdiction lowers taxes (effecting $G$ ) and/or relaxes environmental regulations (lowering utility directly) thus setting up a characteristic economic tradeoff.

Will competition among small jurisdictions with agglomeration forces lead to efficiency? Social efficiency requires the maximization of the representative resident's utility subject to (i) utility in all other jurisdictions is equalized to a fixed level, (ii) aggregate production and consumption clear, and (iii) the mobile capital stock is allocated entirely among jurisdictions (clear). The resulting social optimum conditions from the standard model (without agglomeration) are well known (see Oates and Schwab 1988; Wilson 1999) therefore derivation discussion is keep to a minimum. Traditional social efficiency becomes,

$$
\begin{aligned}
& \operatorname{MRS}_{G, x}=\frac{u_{G}}{u_{x}}=1 \quad \forall i \text { jurisdictions, } \\
& -\operatorname{MRS}_{e, x}=\frac{-u_{e}}{u_{x}}=f_{e} \quad \forall i, \\
& f_{k}^{i}=f_{k}^{j} \quad \forall i, j \quad j \neq i .
\end{aligned}
$$

Equation (7) represents the familiar 'Samuelson condition' for the provision of public goods (Wilson 1986). This appropriate optimality condition suggests that the marginal rate of substitution $\left(M R S_{G, x}\right)$ between the public good and consumption equals the marginal cost of providing an incremental increase in the public good. Given equation (6), the marginal rate of transformation in this context is one for one. Equation (8) shows that jurisdictions should choose a combination of environmental quality and consumption such that the marginal rate of substitution between the two equals the marginal product of emissions (recall that $\left.u_{e}<0\right) .{ }^{6}$ Equation (8) then represents a Samuelson rule for environmental quality, if so inclined (Kunce and Shogren 2005). Equation (9) shows the optimal clearing condition for mobile capital. Jurisdictional authorities, taking into account the presence of external economies, choose the tax rate on capital $(t)$ and the level of environmental quality $(e)$ that maximizes the representative resident's utility. First order conditions become,

$$
\frac{u_{G}}{u_{x}} \frac{\partial G}{\partial t}+\frac{\partial x}{\partial t}=\frac{u_{G}}{u_{x}} \frac{\partial G}{\partial e}+\frac{\partial x}{\partial e}+\frac{u_{e}}{u_{x}}=0
$$

6 Alternatively, given production with a scalar constant, $\bar{a} f(k, e)$, the marginal product with respect to emissions becomes $\bar{a} f_{e}(k, e)=\bar{a} f_{e}$. 
where by differentiating equation (6) with respect to $t$ yields, ${ }^{7}$

$$
\begin{aligned}
& \frac{\partial x}{\partial t}=f a_{k} \frac{\partial k}{\partial t}+a\left(f_{k} \frac{\partial k}{\partial t}+f_{e}\left[\frac{\partial e}{\partial t}=0\right]\right)-r \frac{\partial k}{\partial t}-\left(t \frac{\partial k}{\partial t}+k\right) \\
& =f a_{k} \frac{\partial k}{\partial t}-k .
\end{aligned}
$$

Equation (3) provides the optimality condition necessary to derive $\partial k / \partial t$ using the implicit function theorem where,

$$
\begin{aligned}
& I_{1}: f_{k} a-t-r=0 \\
& \frac{\partial k}{\partial t}=-\frac{\partial I_{1} / \partial t}{\partial I_{1} / \partial k}=\frac{1}{\left(f_{k} a_{k}+a f_{k k}\right)} .
\end{aligned}
$$

Substituting equations (11) and (12) into the left-side equality in equation (10) yields, ${ }^{8}$

$$
(t): \frac{u_{G}}{u_{x}}\left(\frac{t}{\left(f_{k} a_{k}+a f_{k k}\right)}+k\right)+\frac{f a_{k}}{\left(f_{k} a_{k}+a f_{k k}\right)}-k=0 .
$$

Following the same derivation procedure, the first order condition with respect to $e$ becomes,

$$
\text { (e): } \frac{u_{G}}{u_{x}}\left(\frac{-t a f_{k e}}{\left(f_{k} a_{k}+a f_{k k}\right)}\right)-\frac{f a_{k} a f_{k e}}{\left(f_{k} a_{k}+a f_{k k}\right)}+\frac{u_{e}}{u_{x}}+a f_{e}=0 .
$$

An important component of equation (14) is how mobile capital is effected by changes in allowed pollution emissions. Following the derivation of equation (12),

$$
\frac{\partial k}{\partial e}=\frac{-a f_{k e}}{\left(f_{k} a_{k}+a f_{k k}\right)} .
$$

${ }^{7}$ Parentheses use in the derivation equations is solely algebraic.

8 This FOC is analogous to equation (9) in Fernández (2005). 
Solving equations (13) and (14) simultaneously yields the utility maximizing conditions, with suitable rearrangement,

$$
\begin{aligned}
& t=-\left(\frac{f a_{k}+k\left(\frac{u_{G}}{u_{x}}-1\right)\left(f_{k} a_{k}+a f_{k k}\right)}{\frac{u_{G}}{u_{x}}}\right), \\
& \frac{-u_{e}}{u_{x}}=a f_{e}+k a f_{k e}\left(\frac{u_{G}}{u_{x}}-1\right) .
\end{aligned}
$$

\section{Optimal Condition Propositions}

Proposition 1. Assume that jurisdictions can provide public goods efficiently as shown in equation (7). Additionally, assume the base case of no agglomeration forces where $a(k)$ is constant $(\bar{a})$, thus implying $a_{k}=0 . \quad$ Equation (16) now yields, $t=0$. Equation (17) becomes, $-u_{e} / u_{x}=\bar{a} f_{e}$, hence efficiency is achieved comparable to traditional models.

Jurisdictions will choose a capital tax rate of zero when alternative non-distortionary taxation is available ${ }^{9}$ and agglomeration forces are not present. In this fiscal 'firstbest' equilibrium, the efficient provision of $G$ triggers disincentives to chase capital with lax environmental standards. Therefore, maximizing behavior implies that a jurisdiction will set $e$ so that the change in local consumption equals the marginal willingness to pay for environmental quality. Since the change in jurisdictional consumption equals the change in output with respect to a marginal change in $e$, the marginal willingness to pay for environmental quality equals the marginal product of the environment. ${ }^{10}$

Proposition 2. Assume jurisdictions with agglomeration forces present are restricted to taxation of mobile capital in order to finance $G$ (see equation (4)). The well received result of this tax policy is the under-provision of $G\left(u_{G} / u_{x}>1\right)$. A meaningful (interior) equilibrium then requires the numerator in equation (16) to be negative forcing $t>0$. Moreover, assume that the marginal product of capital is increasing in emissions $\left(f_{k e}>1\right)$. Jurisdictions will choose lax environmental standards (higher e).

${ }^{9}$ For example, fixed labor (head) or land taxation that is free to vary (see Kunce 2000).

10 A review of an earlier version of this paper points to a case for capital tax subsidies, analogous to Garcia-Milà and McGuire (2001), under this proposition. Because the focus of this examination is decentralized environmental policy, the reviewer's point is explored in the Appendix. 
In order for the numerator of equation (16) to be negative, given the under-provision of public goods, the effect on the marginal product of capital from agglomeration has to be dominated by the diminishing marginal productivity of capital $\left(f_{k} a_{k}+a f_{k k}<0\right)$. Moreover, the term $k\left(\left[u_{G} / u_{x}\right]-1\right)\left(f_{k} a_{k}+a f_{k k}\right)$ must be sufficiently negative relative to the term $f a_{k}$. Krogstrup (2008) refers to this as "agglomeration forces of moderate strength".

The assumption that the marginal product of capital is increasing in emissions appears natural and is reinforced by Euler's properties of linearly homogeneous functions (Oates and Schwab 1988). With capital-emissions complementarity, capital is drawn to jurisdictions with lax standards (see equation (15)). Accordingly, the marginal social benefit from improving the environment now exceeds the marginal social cost, as the far right-hand-side of equation (17) and $a\left(k^{*}\right)$ are positive, thus the level of allowed emissions $(e)$ will be set higher than the social optimum. Distortionary capital taxation paired with moderate agglomeration economies provides incentives for jurisdictions to attract capital with relaxed environmental standards.

Proposition 3. Assume that external economies dominate the marginal product of capital $\left(f_{k} a_{k}+a f_{k k}>0\right)$. Moreover, capital taxation alone finances $G$. A meaningful (interior) equilibrium requires the bracketed portion of equation (16) to be negative, forcing $t>0$. Assuming that the marginal product of capital is increasing in emissions $\left(f_{k e}>1\right)$, jurisdictions possess incentives to choose overly stringent environmental standards (lower e).

In order for the bracketed part of equation (16) to be negative, given strong agglomeration forces, the marginal willingness to pay for public goods must be less than one yet greater than zero $\left(1>u_{G} / u_{x}>0\right)$. Again, the term $k\left(\left[u_{G} / u_{x}\right]-1\right)\left(f_{k} a_{k}+a f_{k k}\right) \quad$ must be sufficiently negative relative to the term $f a_{k}$.

Note that the denominator of the bracketed portion of equation (16) is less than one (but positive) hence the potential for a sufficiently large equilibrium capital tax rate. Strong external economies provide jurisdictions internal forces to attract and keep capital, heavily tax it and over-provide local public goods.

Accordingly, the marginal willingness to pay for environment quality is now less than the marginal cost as long as the far right-hand-side of equation (17) is adequately negative. Given this local condition, the level of allowed emissions $(e)$ will be set lower than the social optimum. Strong agglomeration economies allow for the over-provision of public goods thus providing incentives for jurisdictions to over-protect the environment. In effect, strong agglomeration forces replace a jurisdiction's enthusiasm to lure capital with low tax rates and lax environmental standards. 


\section{Concluding Remarks}

Non-conventional results herein suggest that when agglomeration forces are strong in a jurisdiction, capitals' response to local governments' policy levers is subdued. Less responsive capital acts as a quasi-fixed factor allowing jurisdictions to tax it heavily and set inefficiently stringent environmental standards - with little fear of capital flight. In effect, decentralized standard setting, in the presence of strong external economies, is sub-optimal, but in the right direction for those concerned about enhanced environmental quality. A race-to-the-top, if you will. In any case, what is clear, with or without agglomeration forces present, decentralized efficiency in a second-best fiscal setting is a target difficult to hit.

The current state of the empirical literature on environmental standards linked with agglomeration is not entirely helpful in sorting out these matters (see Pang et al 2021 for a related, recent review). Rather important open questions remain: (i) do local governments set environmental regulations inefficiently, how and why, and (ii) what are the resulting welfare implications? The model developed herein can provide useful insight to help frame future empirical efforts to address these questions. For example, in addition to the sub-optimal agglomeration influences, the model reveals that the linkage of tax and environmental policy should be addressed empirically. This suggests that empirical efforts should study local fiscal tax systems in conjunction with environmental policy to determine the extent to which they jointly promote or curtail decentralized efficiency. Jurisdictions that rely solely on distortive tax instruments, like capital taxes, may possess strong incentives to choose inefficient levels of environmental quality.

\section{References}

[1] Oates, W. (2002). A reconsideration of environmental federalism, in Recent Advances in Environmental Economics, Eds: J. A. List and A. de Zeeuw, Edward Elgar Publishing: UK, pp. 1-32.

[2] Cumberland, J. (1981). Efficiency and equity in interregional environmental management. Review of Regional Studies 2, pp. 1-9.

[3] Oates, W. and Schwab, R. (1988). Economic competition among jurisdictions: Efficiency enhancing or distortion inducing. Journal of Public Economics 35, pp. 333-354.

[4] Henderson, J. (1988). Urban Development. Theory, Fact and Illusion. Oxford University Press.

[5] Krugman, P. (1991). Increasing returns and economic geography. Journal of Political Economy 99, pp. 483-499.

[6] Krogstrup, S. (2008). Standard tax competition and increasing returns. Journal of Public Economic Theory 10(4), pp. 547-561.

[7] Zeng, D. and Zhao, L. (2009). Pollution havens and industrial agglomeration. Journal of Environmental Economics and Management 58(2), pp. 141-153.

[8] Kunce, M. and Shogren, J. (2002). On environmental federalism and direct emission control. Journal of Urban Economics 51, pp. 238-245. 
[9] Kunce, M. (2022). Efficient decentralized environmental standards from a model of strategic interjurisdictional competition. British Journal of Environmental Sciences 10(1), pp. 1-12.

[10] List, J. and Mason, C. (2001). Optimal institutional arrangements for transboundary pollutants in a second-best world: Evidence from a differential game with asymmetric players. Journal of Environmental Economics and Management 42, pp. 277-296.

[11] Wilson, J. (1986). A theory of interregional tax competition. Journal of Urban Economics 19, pp. 296-315.

[12] Wilson, J. (1999). Theories of tax competition. National Tax Journal 52, pp. 269-304.

[13] Kunce, M. and Shogren, J. (2005). On interjurisdictional competition and environmental federalsim. Journal of Environmental Economics and Management 50, pp. 212-224.

[14] Fernández, G. (2005). A note on tax competition in the presence of agglomeration economies. Regional Science and Urban Economics 35, pp. 837-847.

[15] Kunce, M. (2000). A Nash tax Game extending the generality of the Henry George theorem. Economics Letters 66(2), pp. 229-233.

[16] Garcia-Milà, T. and McGuire, T. (2001). Tax incentives and the city. Paper prepared for the Brookings-Wharton conference on urban affairs, Washington, DC.

[17] Pang, R., Zheng, D. and Shi, M. (2021). Agglomeration externalities and the nonlinear performance of environmental regulation. Growth and Change 52(3), pp. 1701-1731.

\section{Appendix}

Garcia-Milà and McGuire (2001) were interested in exploring whether it is socially optimal for cities to offer tax incentives to attract capital. By introducing external economies ('concentration externalities') they find it is efficient for communities to offer tax rates below 'benefit' tax levels in order to attract capital which increases the productivity of existing firms. Tax incentives become a means of internalizing the positive externality of agglomeration forces. Their result hinges on the assumption that local governments have access to 'multiple tax sources' having the potential to be non-distortionary (first-best). Proposition 1, in the text herein, assumes jurisdictions have this access as well. Suppose jurisdictions provide public goods efficiently by using fixed factor taxation that can vary freely. When agglomeration forces are present, equation (16) in the text becomes, $t=-f a_{k}$. Additionally, equation (17) reduces to, $-u_{e} / u_{x}=a f_{e}$. The presence of external economies and a local government's unfettered access to 'first-best' taxation provides jurisdictions incentives to subsidize mobile capital in exchange for higher incomes hence consumption. 